\title{
Improvement of the Extraction Process for High Commercial Value Pigments from Desmodesmus sp. Microalgae
}

\author{
Aline T. Soares, ${ }^{a}$ Jair G. Marques Júnior, ${ }^{a}$ Rafael G. Lopes, ${ }^{b}$ Roberto B. Derner ${ }^{b}$ and \\ Nelson R. Antoniosi Filho $*, a$ \\ ${ }^{a}$ Laboratório de Métodos de Extração e Separação (LAMES), Instituto de Química, Universidade \\ Federal de Goiás, Campus II (Samambaia), 74690-900 Goiânia-GO, Brazil \\ ${ }^{b}$ Laboratório de Cultivo de Algas (LCA), Departamento de Aquicultura, Centro de Ciências \\ Agrárias, Universidade Federal de Santa Catarina, 88061-600 Florianópolis-SC, Brazil
}

\begin{abstract}
Considering the high interest and commercial value of pigments from microalgae, this study aimed to stablish the best lutein and $\beta$-carotene extraction method for Desmodesmus sp., a microalgae with high biomass production. The evaluation was done considering the best solvent or solvent mixture, number of extractions, pre-treatment of dry biomass with acetone, saponification in methanol and ethanol and stability evaluation of the obtained extract. Among achieved results, the best solvent extractor was a hexane:ethanol mixture in a 1:1 (v/v) proportion. In order to obtain maximum yield, the pattern stablished includes six extractions performed for 40 minutes. Stability tests presented that xanthophylls and carotenes pigments were more stable in methanol and that xanthophylls and carotenes pigments were less negatively affected than chlorophylls in the methanolic extract. Chromatographic identification and quantification of pigments from Desmodesmus sp. microalgae revealed that its major constituents are trans-zeaxanthin, chlorophyll b, $\beta$-carotene and trans-lutein.
\end{abstract}

Keywords: microalgae, pigments, extraction, saponification, HPLC-DAD

\section{Introduction}

Microalgae are single cell microorganisms capable of transforming sunlight into chemical energy by photosynthesis. Many bioactive compounds of commercial, medicinal and scientific interest are obtained from microalgae, such as pigments, antioxidants, fatty acids, enzymes, polymers, pharmaceuticals ${ }^{1}$ and, most recently, fatty raw material for biodiesel production. ${ }^{2,3}$

Each microalgae species presents a specific class of pigments. Carotenoids and chlorophylls are the most common. Among chlorophylls, chlorophyll $a$ is the major photosynthetic pigment in phytoplankton and it has been commonly used as an indicator of biomass production.

Carotenoids are classified as carotenes or hydrocarbon carotenoids made of carbon and hydrogen only, ${ }^{1}$ such as lycopene and $\beta$-carotene, and xanthophylls or oxygenated carotenoids, which may contain epoxides, carbonylic, hydroxylic, methoxy and carboxylic acids groups.

*e-mail: nelson@quimica.ufg.br
Examples of xantophylls are lutein, violaxanthin, canthaxanthin and zeaxanthin. ${ }^{4}$

Many carotenoids and xanthophylls have high commercial value, so there is a great interest in obtaining such substances directly from living organisms. Microalgae can provide pigments in an easy way, but is necessary finding the species that have the expected pigments and evaluate the best extraction method for these substances, in order to achieve high yields, using low-cost and toxicity solvents.

Extraction efficiency will depend on the solvent ability to solubilize pigments without modifying its structures. ${ }^{5}$ Therefore, solvent selection is an important step in pigments extraction, presenting high efficiency and selectivity with the compounds being extracted.

Most microalgae carotenoids extraction studies involve a single solvent extraction. However, binary extraction system studies can be found in literature, as in Aburai et $a l .,{ }^{1}$ which used dichloromethane (DCM) and methanol to perform pigments extraction in four microalgae species. Solovchenko et al. ${ }^{6}$ extracted microalgae Desmodesmus sp. pigments using chloroform and methanol. The use of 
ternary systems, ${ }^{7}$ quaternary systems ${ }^{8,9}$ and supercritical fluid extraction ${ }^{10}$ are also found.

Other determinant factors for pigments extraction yield are: (i) time of contact between sample and solvent and (ii) the technique (mechanical or non-mechanical) applied in order to break cell wall. ${ }^{11}$ Currently, some works show the use of ultrasound-assisted extraction (UEA) $)^{12,13}$ and of microwave and vacuum microwave-assisted extraction (MAE and VMAE). ${ }^{14,15}$

Aiming to simplify pigments separation and to obtain free pigments, some methods suggest pigments saponification. Most of the methods use potassium hydroxide $(\mathrm{KOH})$ alkaline saponification in ethanol or methanol. ${ }^{1,9,16-18}$ However, this treatment leads to degradation and loss of information about the native compounds. In turn, the non-saponified extracts present more complex chromatograms and more pigment information, such as esterified xanthophyll.

Considering the various possibilities to accomplish microalgae pigments extraction and questioning which procedure would be more useful and suitable, the aim of this study was to evaluate the yield of $\beta$-carotene and lutein extraction from Desmodesmus sp. microalgae. For this, it were evaluated the following experimental parameters: (i) application of ultrasound technique using different proportions of the extractor solvents; (ii) evaluation of the number of extractions necessary to achieve the best extract yield; (iii) performing pre-treatment of dry biomass with acetone followed by solvent extraction; (iv) application of ethanolic and methanolic $\mathrm{KOH}$ saponification, both of them with or without pre-treatment of dry biomass with acetone and followed by solvent extraction; ( $v$ ) evaluating extract stability in methanol, DCM, hexane and methanol:DCM $(1: 1, \mathrm{v} / \mathrm{v})$; and ( vi) evaluating of qualitative and quantitative pigments profile regarding to different extraction methods. Defining the best extraction system will be an important step, ascribing values to microalgae productive chain.

\section{Experimental}

\section{Materials}

Sodium sulfate, potassium hydroxide, hexane, ethanol and acetone were acquired at Neon Analytical Reagents (São Paulo, SP, Brazil). High performance liquid chromatography (HPLC) solvents (methanol, acetonitrile and dichloromethane) were obtained from J. T. Baker (Tokyo, Japan). Deionized water was obtained at Elix water purification system (Millipore, Billerica, MA, USA). The chlorophyll $a$, trans-lutein and trans- $\beta$-carotene standards were acquired from Sigma-Aldrich (St. Louis, MO, USA).
Extracts were filtered in a polytetrafluoroethylene (PTFE) sterile membrane $(-0.22 \mu \mathrm{m} \times 25 \mathrm{~mm})$. Analytical separation was performed in a YMC30 column $(250 \times 4.6 \mathrm{~mm}, 5 \mu \mathrm{m})$ by Waters (Milford, MA, USA).

Instrumentation

HPLC analyses were conducted in Agilent equipment, 1220 Infinity LC (Agilent Technologies, Santa Clara, CA, USA), with column temperature control, binary bomb and diode array detection (DAD). It was used a rotatory evaporator model 344B2, from Quimis (Diadema, SP, Brazil) with vacuum pump, a Unique ultrasonic bath of $200 \mathrm{~W}$ model USC-5000 (Indaiatuba, SP, Brazil) and an incubator with heating and agitation system model 430, from Nova Ética (Vargem Grande do Sul, SP, Brazil).

\section{Microalgae}

The freshwater microalgae Desmodesmus sp. was isolated, identified, cultivated and supplied by Laboratory of Algae Cultivation (LCA) from Federal University of Santa Catarina (Florianópolis, SC, Brazil). The culture media for cultivating microalgae was WC medium (Wright's cryptophyte). ${ }^{19}$ The cultures were grown in glass fiber cylinders containing $100 \mathrm{~L}$ of the respective culture media. Fixtures with fluorescent lamps were used and photosynthetically active radiation (PAR) was measured. Lighting was $150 \mu \mathrm{mol} \mathrm{m}^{-2} \mathrm{~s}^{-1}$ for a complete photoperiod. Pressurized atmospheric air continuously injected at a flow rate of $10 \mathrm{~L} \mathrm{~min}^{-1}$ into each cylinder was enriched with $1 \% \mathrm{CO}_{2}$ (100\% purity). The temperature of the cultivation room was kept at $25 \pm 2{ }^{\circ} \mathrm{C}$ using air conditioners. Biomass was separated by the addition of a polyacrylamide cationic flocculant Flopam FO $4400 \mathrm{SH}$ in a $15 \mathrm{mg} \mathrm{L}^{-1}$ culture dosage, produced by SNF Floerger (Andrézieux-Bouthéon, France). After flocculation and sedimentation, biomass was filtered through a screen and dried in an oven at $50{ }^{\circ} \mathrm{C}$ for $24 \mathrm{~h}$. The final residual water was $5 \%$.

\section{Pigments extraction using solvents in ultrasound}

Pigments extraction was performed by ultrasound technique. Extractor solvent and extraction time were evaluated. Solvents were chosen based on their less toxicity and cost, on their higher ability to extract pigments, and their capacity to be recovered from distillation. Thus, the solvents tested were: (i) hexane; (ii) acetone; (iii) hexane:ethanol:acetone (10:6:7, v/v/v); (iv) hexane:ethanol in $1: 1 ; 1: 2,1: 3 ; 2: 1,3: 1$ and $4: 1(\mathrm{v} / \mathrm{v})$ proportion; and (v) ethanol. 
Extraction method was based on Inbaraj et al. ${ }^{8}$ Approximately $500 \mathrm{mg}$ of Desmodesmus sp. was weighted in an erlenmeyer flask and $15 \mathrm{~mL}$ of the extractor solvent to be tested were added. This mixture was left in ultrasonic bath for $40 \mathrm{~min}$ at room temperature $\left(23 \pm 2{ }^{\circ} \mathrm{C}\right)$. After, $7.5 \mathrm{~mL}$ of $\mathrm{Na}_{2} \mathrm{SO}_{4} 10 \%$ aqueous solution was added, shaken by hand for $30 \mathrm{~s}$ and left to rest until phases were separated. The upper phase, rich in pigments, was collected and saved in a round-bottom flask.

The residue inside the erlenmeyer was again extracted in ultrasound with $10 \mathrm{~mL}$ of extractor solvent for $40 \mathrm{~min}$ and left to rest until phase separation. The upper phase was collected and added to the first extraction, which was in a round-bottom flask. This procedure was repeated for four times, totaling five extractions. The combined upper phases, which were rich in pigments, were evaporated in a rotatory evaporator, dissolved in $2.5 \mathrm{~mL}$ of a methanol:dichloromethane mixture $(1: 1, \mathrm{v} / \mathrm{v})$ and filtered in a PTFE sterile membrane for HPLC analysis. Extractions were made in triplicate and HPLC-DAD analysis was made in duplicate. After selecting the best extractor solvent, extraction time was tested and varied from 120 to $320 \mathrm{~min}$.

Pigments extraction with and without previous acetone treatment

The following procedures were evaluated: (i) biomass extraction using only hexane:ethanol $(1: 1, \mathrm{v} / \mathrm{v})$, and (ii) biomass extraction using hexane:ethanol $(1: 1, \mathrm{v} / \mathrm{v})$ after previous acetone treatment of dry biomass.

For experiments involving the previous acetone treatment, about $500 \mathrm{mg}$ of dry Desmodesmus sp. sample was weighted in a $250 \mathrm{~mL}$ Erlenmeyer and $5 \mathrm{~mL}$ of acetone were added. The sample was left in ultrasonic bath at room temperature $\left(23 \pm 2{ }^{\circ} \mathrm{C}\right)$ for $30 \mathrm{~min}, 1$ and $2 \mathrm{~h}$. At the end of the pre-treatment process, acetone was recovered through simple distillation and the obtained extract was submitted to pigments extraction as described above, with hexane:ethanol $(1: 1, \mathrm{v} / \mathrm{v})$ solution. This procedure was repeated six times, totaling $240 \mathrm{~min}$.

\section{Pigments saponification}

Two experiments were evaluated for saponification process: the first one was alkaline saponification in (i) methanol and (ii) ethanol, followed by free pigments extraction with hexane:ethanol $(1: 1, v / v)$, repeated for six times of $40 \mathrm{~min}$; and the second experiment tested the influence of previous pre-treatment of the biomass with acetone before alkaline saponification in (i) methanol and (ii) ethanol followed by free pigments extraction with hexane:ethanol $(1: 1, \mathrm{v} / \mathrm{v})$, repeated for six times of $40 \mathrm{~min}$. Acetone treatment was performed as described in Pigments extraction with and without previous acetone treatment section.

For the saponification reaction, $8 \%(\mathrm{v} / \mathrm{v})$ methanolic and ethanolic $\mathrm{KOH}$ solutions were tested. Five milliliter of alkaline alcoholic solution was added to both dry and acetone pre-treated biomass. The resulting mixture was stirred in an incubator at $200 \mathrm{rpm}$ at $60{ }^{\circ} \mathrm{C}$ for one hour. After saponification, the extract inside the Erlenmeyer was submitted to pigment extraction as described above, using a hexane:ethanol $(1: 1, \mathrm{v} / \mathrm{v})$ solution, for $40 \mathrm{~min}$ and repeated for six times, totaling $240 \mathrm{~min}$.

\section{Extract stability study}

About $2 \mathrm{~g}$ of dry biomass was weighted and extracted with hexane:ethanol (1:1, v/v), as described above. Extract was dissolved in $10 \mathrm{~mL}$ of DCM and four aliquots $(2.5 \mathrm{~mL})$ were transferred to four previously weighted round-bottom flasks. These four solutions were concentrated in rotary evaporator and the extract obtained in each flask was dissolved in $2.5 \mathrm{~mL}$ of the test solvent (DCM, methanol, hexane or DCM:methanol $(1: 1, \mathrm{v} / \mathrm{v})$. This procedure led to four new extracts with final concentrations of $22.8 \mathrm{mg} \mathrm{mL}^{-1}$ for extracts dissolved in methanol and DCM, $26 \mathrm{mg} \mathrm{mL}^{-1}$ for DCM:methanol solution and $26.4 \mathrm{mg} \mathrm{mL}^{-1}$ for hexane solution. Each solution was filtered in a sterile PTFE membrane and stored in an amber vial for HPLC-DAD chromatographic analysis. Each sample was analyzed every four hour totalizing eight points in $32 \mathrm{~h}$. The autosampler in HPLC-DAD system was maintained at temperature of $23 \pm 2.0^{\circ} \mathrm{C}$ and in absence of light.

\section{Chromatographic conditions}

Chromatographic analysis method was based on Inbaraj et al. ${ }^{8}$ HPCL-DAD mobile phase was (A) methanol:acetonitrile:water $(84: 14: 2, \mathrm{v} / \mathrm{v} / \mathrm{v})$ and (B) dichloromethane, using the gradient conditions: $100 \%$ $\mathrm{A}$ and $0 \% \mathrm{~B}$ for $14 \mathrm{~min} ; 95 \% \mathrm{~A}$ for $25 \mathrm{~min} ; 75 \% \mathrm{~A}$ for $30 \mathrm{~min} ; 74 \%$ A for $35 \mathrm{~min} ; 45 \% \mathrm{~A}$ for $50 \mathrm{~min}$; and returning to $100 \% \mathrm{~A}$ at $55 \mathrm{~min}$, in $60 \mathrm{~min}$ of analysis. Column oven was kept at $23 \pm 2{ }^{\circ} \mathrm{C}$. Extract injection volume was $20 \mu \mathrm{L}$. Mobile phase was pumped in $1 \mathrm{ml} \mathrm{min}{ }^{-1}$ flow. DAD was operated from 250 to $700 \mathrm{~nm}$ and detection wavelength at $450 \mathrm{~nm}$. Comparison between retention times and peaks absorption spectrum were used for pigments identification. cis and trans isomers of pigments were identified based on previous studies. ${ }^{9,20-22}$ 


\section{Pigments quantification}

Pigments were quantified by HPLC using calibration curve from chlorophyll $a$, trans-lutein and trans- $\beta$-carotene standards, with six different concentrations $(1,5,10,15,30$ and $\left.60 \mu \mathrm{g} \mathrm{mL}^{-1}\right)$. The curve was prepared plotting standard concentration vs. area. Linear regression was calculated at Microsoft Excel (Microsoft Corp., Redmond, WA, USA), leading to a correlation coefficient (r) larger than 0.9995.

Analysis of variance (ANOVA) was carried out to determine if at least one pigment extraction conditions were different from the others. Then, the $t$-test was employed to identify differences among mean values. The ANOVA were performed using Microsoft Excel (Microsoft Corp., Redmond, WA, USA). Hypotheses were tested with a level of significance of $p<0.05$.

Determining limits of quantification (LOQ) and detection (LOD)

Three trans- $\beta$-carotene solutions standards were prepared $\left(1,5\right.$ and $\left.10 \mu \mathrm{g} \mathrm{mL}^{-1}\right)$ and analyzed by HPLC in triplicate, resulting in three calibration curves plotting concentration vs. area. Limit of quantification (LOQ) was calculated based on the equation 1 :

$\mathrm{LOQ}=10\left(\frac{\sigma}{\mathrm{s}}\right)$

and limit of detection (LOD) was calculated based on equation 2 :

$\mathrm{LOD}=3.3\left(\frac{\sigma}{\mathrm{s}}\right)$

where in both equations $\mathrm{s}$ is the interception standard deviation and $\sigma$ is the straight line inclination average, from which values of 0.066 and $0.022 \mu \mathrm{g} \mathrm{mL}^{-1}$ were obtained, respectively.

\section{Results and Discussion}

\section{Effect of solvent type}

Figure 1 shows lutein and $\beta$-carotene extraction yields from Desmodesmus sp. biomass in different extractor solvent mixtures. The analysis of variance revealed that lutein and $\beta$-carotene extractions methodologies were significantly different. The best condition for these pigments extraction was the hexane:ethanol $(1: 1, \mathrm{v} / \mathrm{v})$ mixture, which led to $324.65 \pm 11.77 \mu \mathrm{g} \mathrm{g}^{-1}$ to lutein and $158.44 \pm 8.51 \mu \mathrm{g} \mathrm{g}^{-1}$ to $\beta$-carotene content. It is important to highlight that the second best condition used for lutein extraction was the hexane:ethanol $(4: 1, \mathrm{v} / \mathrm{v})$ mixture and for $\beta$-carotene was hexane:ethanol:acetone (10:6:7, v/v/v), which presented $305.83 \pm 4.92 \mu \mathrm{g} \mathrm{g}^{-1}$ and $125.47 \pm 6.7 \mu \mathrm{g} \mathrm{g}^{-1}$ yield, respectively. For lutein extraction, the $t$-test showed no significant difference between the highest extraction yields, however for $\beta$-carotene it was observed distinction among the mean values.

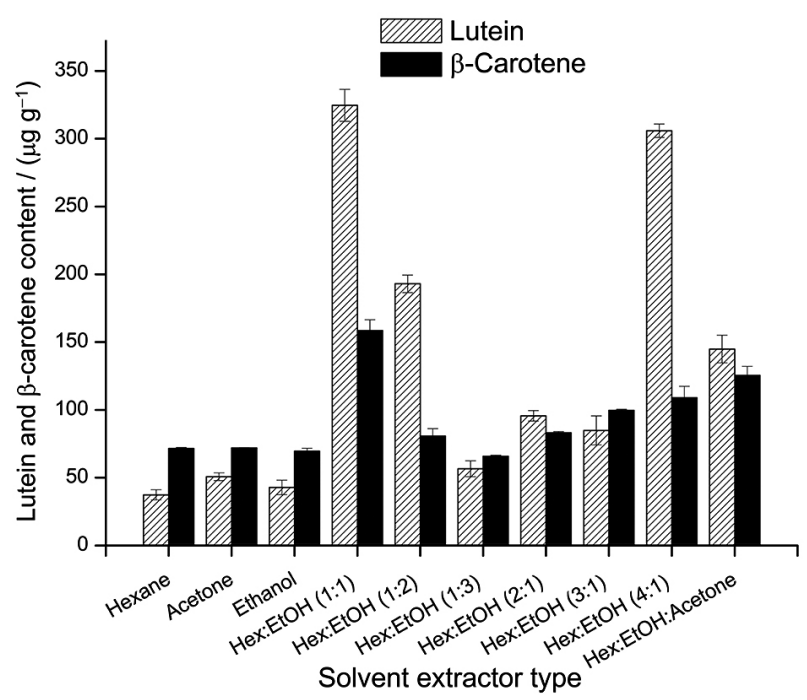

Figure 1. Lutein and $\beta$-carotene content in relation of extractor solvent type. Hex: Hexane; EtOH: ethanol.

By increasing ethanol content in hexane:ethanol mixture, a decrement in $\beta$-carotene and lutein extract yield for Desmodesmus sp. microalgae was observed. This decrement may be explained due to the greater mixture polarity in the presence of ethanol. Furthermore, ethanol is miscible with the sodium sulfate solution water, thus part of the extract may have been retained in aqueous phase. Hexane:ethanol (1:4, $\mathrm{v} / \mathrm{v})$ mixture was tested, but when sodium sulfate solution was added, it was not generated a two-phase system, leading to an undefined phase separation.

An increase in hexane content in the hexane:ethanol mixture was tested and the proportion $4: 1(\mathrm{v} / \mathrm{v})$ provided the best result, even though it was not enough to extract all pigments. Single solvent extractions (hexane, acetone or ethanol) offer similar efficiency in the extract yield for both lutein and $\beta$-carotene. This can explain low yields obtained in the industrial process, as described by Dey and Rathod. ${ }^{18}$ In addition to that, Wang and $\mathrm{Liu}^{23}$ described that the acetone:petroleum ether mixture $(1: 1, \mathrm{v} / \mathrm{v})$ presented better results in pigment extraction of colza biomass when compared to single solvent extractions.

The chromatogram of pigments extracted from Desmodesmus sp. microalgae biomass using hexane:ethanol $(1: 1, v / v)$ is shown in Figure 2a. Mobile phase gradient developed by Hibaraj et al. ${ }^{8}$ and used in this study for 
Desmodesmus sp. microalgae allowed the separation of 23 carotenoids in $50 \mathrm{~min}$. The pigments were identified considering the ultraviolet-visible spectra characteristics, chromatographic behavior, co-elution with standards and comparison of data from the literature. trans-zeaxanthin, chlorophyll $b$, carotenes and trans-lutein are the major pigments, representing 23.9, 21.7, 20 and $11.4 \%$ of total pigments, respectively. Violaxanthin, antheraxanthin, neoxanthin were identified as demonstrated Solovchenko et al. ${ }^{6}$ and it was observed some other minor peaks (Table 1). Hexane:ethanol (1:1, v/v) extraction led to $2842.7 \mu \mathrm{g} \mathrm{g}{ }^{-1}$ yield of total pigments from dry microalgae biomass.

Chlorophyll and its derivatives present two major absorption bands in the visible region due to $\pi$ electrons
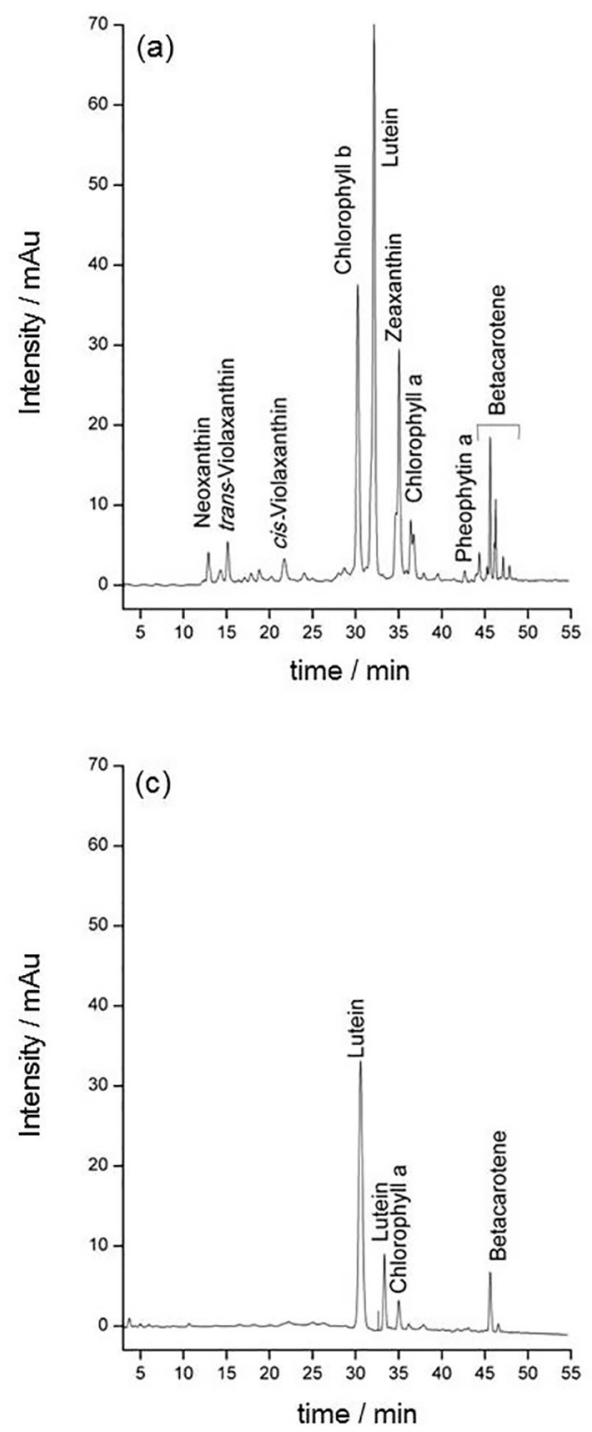

delocalization of the porphyrin, which are a band in the red region ( $\mathrm{Q}$ band) and another in the blue region (Soret or B band). The absorption bands values in the red and blue region for chlorophyll $a$ are 664 and $432 \mathrm{~nm}$, respectively. For chlorophyll $b$, these values are 652 and $468 \mathrm{~nm}$, respectively. Chlorophyll $b$ has two types of maximum absorption: from 642 to $652 \mathrm{~nm}$ at red region and a second absorption of 465 to $470 \mathrm{~nm}$ at blue region. ${ }^{20,24}$

Pheophytin is a chlorophyll $a$ or $b$ derivative without the central magnesium atom. Pheophytin $a$ presents maximum absorption at 409 and $665.9 \mathrm{~nm}$, whereas in pheophytin $b$, the values are 434 and $653 \mathrm{~nm}$. Desmodesmus sp. extract obtained by using hexane:ethanol $(1: 1, \mathrm{v} / \mathrm{v})$ presented maximum absorption in 666 and $412 \mathrm{~nm}$ for pheophytin $a$ (Table 1). The absorbance intensity rate for Soret and Qy
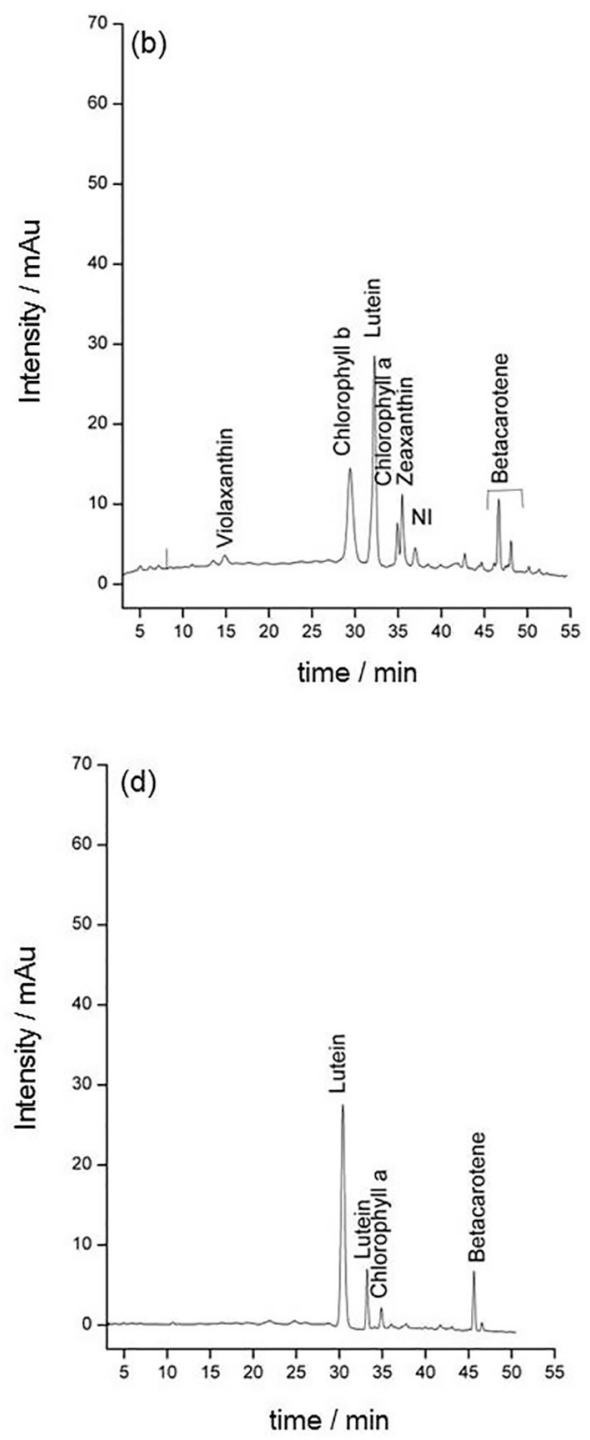

Figure 2. Chromatogram obtained by high performance liquid chromatography with diode array detection (HPLC-DAD) of dry biomass from Desmodesmus sp. microalgae (a) extracted with hexane:ethanol $(1: 1, \mathrm{v} / \mathrm{v})$; (b) treated with acetone for $1 \mathrm{~h}$ followed by hexane:ethanol $(1: 1, \mathrm{v} / \mathrm{v})$ extraction; (c) treated with acetone for $1 \mathrm{~h}$ followed by methanolic saponification and subsequent hexane:ethanol (1:1, v/v) extraction; (d) treated with acetone for $1 \mathrm{~h}$ followed by ethanolic saponification and subsequent hexane:ethanol $(1: 1, \mathrm{v} / \mathrm{v})$ extraction. 
Table 1. Identification of pigments obtained by high performance liquid chromatography with diode array detection (HPLC-DAD) of dry biomass from Desmodesmus sp. microalgae by hexane:ethanol $(1: 1, \mathrm{v} / \mathrm{v})$ extraction

\begin{tabular}{|c|c|c|c|}
\hline Pigment & $\lambda / \mathrm{nm}^{\mathrm{a}, 9}$ & $\lambda / \mathrm{nm}^{\mathrm{b}}$ & Concentration $^{\mathrm{c}} /\left(\mu \mathrm{g} \mathrm{g}^{-1}\right)$ \\
\hline trans-neoxanthin & $416,444,472$ & $414,442,470^{9}$ & $77.9 \pm 1.6$ \\
\hline Neochrome & $400,422,442$ & $398,422,440^{8}$ & $9.6 \pm 0.1$ \\
\hline trans-violaxanthin & $416,440,468$ & $416,440,468^{9}$ & $101.7 \pm 1.1$ \\
\hline 9- or 9'-cis-neoxanthin & $416,438,466$ & $412,436,464^{9}$ & $18.2 \pm 1.5$ \\
\hline cis-neoxanthin & $406,428,456$ & $404,428,458^{8}$ & $22.2 \pm 1.3$ \\
\hline cis-violaxanhtin & $420,444,468$ & $416,440,468^{9}$ & $98.7 \pm 3.6$ \\
\hline Anteraxanthin & $420,444,474$ & $418,442,472^{9}$ & $19.3 \pm 0.6$ \\
\hline Chlorophyll b or b' & 468,652 & $465,652^{22}$ & $615.8 \pm 6.2$ \\
\hline 13- or 13'-cis-lutein & 418,468 & $415,440,464^{8}$ & $2.1 \pm 1.4$ \\
\hline cis-lutein & $424,446,472$ & $422,446,470^{8}$ & $44.8 \pm 1.1$ \\
\hline trans-lutein & $424,446,474$ & $423,446,470^{8}$ & $324.7 \pm 11.7$ \\
\hline cis-zeaxanthin & $422,448,472$ & $422,446,474^{26}$ & $142.5 \pm 4.1$ \\
\hline trans-zeaxanthin & $426,452,478$ & $427,452,476^{8}$ & $679.4 \pm 3.2$ \\
\hline Chlorophyll a or a' & 432,664 & $430,662^{22}$ & $109.1 \pm 0.3$ \\
\hline Pheophythin a or a' & 412,666 & $409,665^{22}$ & $7.6 \pm 1.1$ \\
\hline 9- or 9'-cis- $\alpha$-carotene & $422,454,478$ & $422,452,476^{8}$ & $70.0 \pm 0.5$ \\
\hline trans- $\alpha$-carotene & $428,450,478$ & $426,449,476^{8}$ & $114.9 \pm 3.0$ \\
\hline 13 - or 13 '-cis- $\beta$-carotene & $428,448,476$ & $422,448,474^{26}$ & $80.9 \pm 2.1$ \\
\hline trans- $\beta$-carotene & $428,454,480$ & $430,458,482^{8}$ & $158.4 \pm 8.5$ \\
\hline 9- or 9'-cis- $\beta$-carotene & $426,452,478$ & $428,452,476^{8}$ & $74.4 \pm 1.8$ \\
\hline 9- or 9'-cis- $\beta$-carotene & $426,452,478$ & $428,452,476^{8}$ & $70.5 \pm 1.5$ \\
\hline Total / $\left(\mu \mathrm{g} \mathrm{g}^{-1}\right)$ & - & - & 2842.7 \\
\hline
\end{tabular}

${ }^{\text {a Inline; }}$ breported; ${ }^{\mathrm{c} a v a r a g e} \pm$ SD. ${ }^{8}$ Mobile phase system of methanol:acetonitrile:water (84:14:2, v/v/v) and methylene chloride (100\%); ${ }^{9} \mathrm{mobile}$ phase system of methanol:acetonitrile:water (79:14:7, v/v/v) and methylene chloride (100\%); ${ }^{22}$ mobile phase system of acetonitrile:methanol:ethyl acetate (60:20:20 $\mathrm{v} / \mathrm{v} / \mathrm{v}$, isocratic); ${ }^{26} \mathrm{mobile}$ phase system of methanol:acetonitrile:water $(84: 14: 5, \mathrm{v} / \mathrm{v} / \mathrm{v})$ and methylene chloride $(100 \%)$.

$\left(\mathrm{A}_{\text {Soree }} / \mathrm{A}_{\mathrm{Qy}}\right)$ bands regarding chlorophyll $a$, chlorophyll $b$ and pheophytin $a$ is $1.25,2.8$ and 2.0 , respectively, as already reported. ${ }^{22}$

Violaxanthin, neoxanthin, zeaxanthin, $\beta$-carotene and trans and cis-lutein were identified by comparison with literature data, based on absorption spectrum ${ }^{8,9,21,25-28}$ and retention times.

\section{Extraction time effect}

Hexane:ethanol $(1: 1, \mathrm{v} / \mathrm{v})$ solvent mixture presented the best extract yield for lutein and $\beta$-carotene in Desmodesmus sp. microalgae. Therefore, the effect of extraction time on extract yield was tested using this solvent mixture. The presented data in Figure 3 show lutein and $\beta$-carotene extraction yield in Desmodesmus sp. for different extraction time. The ANOVA showed significance $(p<0.05)$ for both pigments in these extraction times tested.

Lutein extraction yield increases until $240 \mathrm{~min}$ (equivalent to 6 repetitions of $40 \mathrm{~min}$ ). For $\beta$-carotene, the yield increased till $280 \mathrm{~min}$ (equivalent to 7 repetitions of $40 \mathrm{~min}$ ) and it was kept constant up to $320 \mathrm{~min}$. But $t$-test showed no difference between these times and also for $240 \mathrm{~min}$. Increased extraction times leads to higher

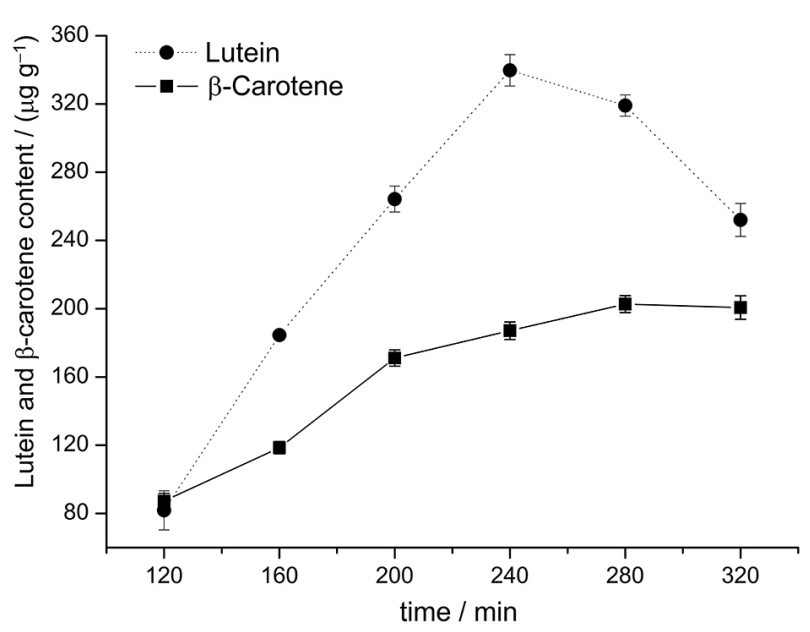

Figure 3. Lutein and $\beta$-carotene content in relation of extraction time. 
extract content because a contact between pigments and solvent eases extraction process up to the point where concentration gradient between microalgae cell and solvent reaches balance. ${ }^{11}$ Lutein yield decrement after reaching the curve peak may be related to extract degradation, after a long contact time with the extractor solvent. For further experiments the procedure will consist of 6 extractions of $40 \mathrm{~min}$, totaling $240 \mathrm{~min}$.

Extractor solvents, when first extractions were observed, presented a darker color than the subsequent extracts, indicating a higher pigment concentration in initial extracts. During the experiment, the increase volume in aqueous phase throughout the extraction process is due to the interaction of ethanol with sodium sulfate solution.

Evaluation on the influence of acetone pre-treatment of dry biomass

Extraction efficiency of pigments and other compounds from microalgae are related to microalgae cell wall destruction, releasing these substances and allowing their interaction with extractor solvent. ${ }^{29}$ Therefore, a biomass pre-treatment with acetone in ultrasonic bath was considered a possible influence in $\beta$-carotene and lutein extraction yield when compared to extraction using only hexane:ethanol $(1: 1, \mathrm{v} / \mathrm{v})$.

Analyzing the chromatogram from Figure $2 b$, pretreatment with acetone followed by hexane:ethanol
$(1: 1, v / v)$ extraction led to a reduction in peaks number and intensity when compared to extraction using only hexane:ethanol (1:1, v/v; Figure 2a). According the identified pigments (Table 2), the predominant presence of $\beta$-carotene, $\alpha$-carotene, chlorophyll and lutein can be observed, as well as smaller quantities of violaxanthin and zeaxanthin. The total pigments concentration extracted from biomass varied from 798.6 to $1282.6 \mu \mathrm{g} \mathrm{g}^{-1}$, corresponding to a reduction of $66.4 \%$ when compared to the extraction using only hexane:ethanol $(1: 1, \mathrm{v} / \mathrm{v})$.

The statistical analysis performed for acetone treatment showed that the effects for both pigments were significant, with $p=0.000074$ to lutein and $p=0.00043$ to $\beta$-carotene. By analyzing Figure 4, hexane:ethanol (1:1, v/v) extraction for lutein was the highest yield method when compared to procedures involving acetone pre-treatment. Pre-treatment with acetone lead to a reduction of $73.5 \%$ in lutein content when conduced for $2 \mathrm{~h}$. This reduction is related to pigment degradation in face of greater contact with acetone and, then, with the extractor solvent.

For $\beta$-carotene extraction, the biomass pre-treatment of $1 \mathrm{~h}$ followed by hexane:ethanol (1:1, v/v) extraction led to greater yield than the other tested methodologies. Thus, pre-treatment with acetone decreases lutein content but it improves $\beta$-carotene yield. Therefore, considering that the $t$ - test for the highest yields from $\beta$-carotene was slightly different $(p=0.047)$ and also one more step for pigments extraction, the procedure with hexane:ethanol $(1: 1, \mathrm{v} / \mathrm{v})$

Table 2. Identification of pigments obtained by high performance liquid chromatography with diode array detection (HPLC-DAD) of dry biomass from Desmodesmus sp. microalgae treated with acetone followed by hexane:ethanol $(1: 1, \mathrm{v} / \mathrm{v})$ extraction; methanolic and ethanolic saponification with or without acetone treatment followed by hexane:ethanol $(1: 1, \mathrm{v} / \mathrm{v})$ extraction

\begin{tabular}{|c|c|c|c|c|c|c|c|c|c|c|c|}
\hline \multirow{3}{*}{ Pigment } & \multicolumn{11}{|c|}{ Concentration / $\left(\mu \mathrm{g} \mathrm{g}^{-1}\right)$} \\
\hline & \multicolumn{3}{|c|}{ Acetone treatment } & \multicolumn{4}{|c|}{ Methanolic saponification } & \multicolumn{4}{|c|}{ Ethanolic saponification } \\
\hline & $30 \mathrm{~min}$ & $1 \mathrm{~h}$ & $2 \mathrm{~h}$ & No AT & $30 \min \mathrm{AT}$ & $1 \mathrm{~h} \mathrm{AT}$ & $2 \mathrm{~h} \mathrm{AT}$ & No AT & $30 \min \mathrm{AT}$ & $1 \mathrm{~h} \mathrm{AT}$ & $2 \mathrm{~h} \mathrm{AT}$ \\
\hline cis-violaxanthin & 29.4 & 57.8 & 32.6 & - & - & - & - & - & - & - & - \\
\hline Chlorophyll b & 280.3 & 257.9 & 153.8 & - & - & - & - & - & - & - & - \\
\hline 9-cis-lutein & 18.9 & 17.9 & 12.1 & 27.2 & 31.5 & 31.0 & 29.9 & 24.9 & 31.2 & 25.7 & 31.8 \\
\hline trans-lutein & 130.5 & 155.8 & 90.9 & 180.9 & 194.2 & 203.0 & 192.7 & 179.8 & 208.9 & 225.8 & 181.8 \\
\hline Chlorophyll a or a' & 31.1 & 4.8 & 10.4 & 5.15 & 7.0 & 9.2 & 7.1 & 6.4 & 3.9 & 3.4 & 3.3 \\
\hline trans-zeaxanthin & 40.9 & 70.5 & 49.1 & - & - & - & - & - & - & - & - \\
\hline Not identified & 5.5 & 7.7 & 5.0 & - & - & - & - & - & - & - & - \\
\hline 9-cis- $\alpha$-carotene & 66.1 & 135.7 & 69.5 & - & - & - & - & - & - & - & - \\
\hline trans- $\beta$-carotene & 146.1 & 268.6 & 157.9 & 124.1 & 121.3 & 163.2 & 136.2 & 145.8 & 167.2 & 156.2 & 140.1 \\
\hline 9-cis- $\beta$-carotene & 125.9 & 123.6 & 122.6 & 63.2 & 63.5 & 69.8 & 65.5 & 65.2 & 68.8 & 65.2 & 65.7 \\
\hline cis- $\beta$-carotene & 90.9 & 180.0 & 91.9 & - & - & - & - & - & - & - & - \\
\hline cis- $\beta$-carotene & 2.9 & 2.2 & 2.8 & - & - & - & - & - & - & - & - \\
\hline Total / $\left(\mu \mathrm{g} \mathrm{g}^{-1}\right)$ & 968.5 & 1282.6 & 798.6 & 400.6 & 417.5 & 476.2 & 431.4 & 422.1 & 480.0 & 476.3 & 422.7 \\
\hline
\end{tabular}

AT: Acetone treatment. 
presents as a better method. On financial aspects, there are no advantages in this kind of treatment, since lutein presents higher price than $\beta$-carotene.

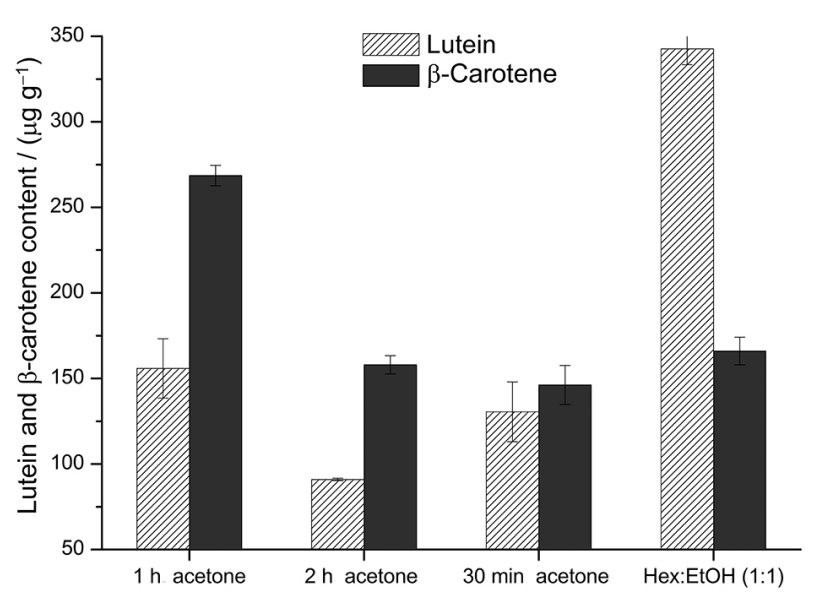

Figure 4. Influence of acetone treatment of dry Desmodesmus sp. microalgae on lutein and $\beta$-carotene content. Hex: Hexane; EtOH: ethanol.

\section{Saponification and pigments extraction}

There is a great interest from the industry in free pigments, in other words, non-esterified, which is achieved by saponification of microalgae biomass. Therefore, alkaline saponification was tested in both solvents, methanol and ethanol. Even though, $\beta$-carotene is a non-esterified carotenoid and it is important to evaluate the influence of saponification process in non-esterified pigments content.

By using saponification, $\beta$-carotene and lutein extraction has been favored when acetone pre-treatment is applied in both methanolic and ethanolic solution for saponification, but the increased was slightly significant. The highest lutein yield was obtained when dry biomass was pre-treated with acetone for $1 \mathrm{~h}$, followed by saponification in ethanol and subsequent hexane:ethanol $(1: 1, \mathrm{v} / \mathrm{v})$ extraction (Figure 5 and Table 2).

For $\beta$-carotene, a better yield was reached within 30 min of acetone pre-treatment when ethanol was used as the saponification reaction solvent (Figure 5 and Table 2). When it was used methanol as solvent on alkaline solution, $\beta$-carotene yield achieved its maximum in $1 \mathrm{~h}$ of pretreatment with acetone.

The $t$-test for methanol and ethanol with or without acetone pre-treatment showed no significance difference $(p>5)$. Based on these results, for $\beta$-carotene extraction the content is similar in $1 \mathrm{~h}$ of pre-treatment with acetone in either methanol or ethanol. However, for lutein extraction the yields under same conditions is slightly different and it is better in ethanol solution. So, considering the methanol toxicity, it is suggested to obtain free pigments from Desmodesmus sp. biomass the use of ethanol saponification reaction.

According to Table 2, which identifies chromatograms peaks from Figures $2 \mathrm{c}$ and $2 \mathrm{~d}$, saponification process releases free pigments (non-esterified), simplifying pigments extraction. In addition, saponification also provides esterified pigments identification, as shown for the identification of xanthophyll esters. ${ }^{16,17}$

Methanol (Figure 2c) and ethanol (Figure 2d) alkaline saponification also led to the disappearance of some peaks that were usually present in ordinary solvent extractions. Saponification reaction, either from dry biomass or acetone

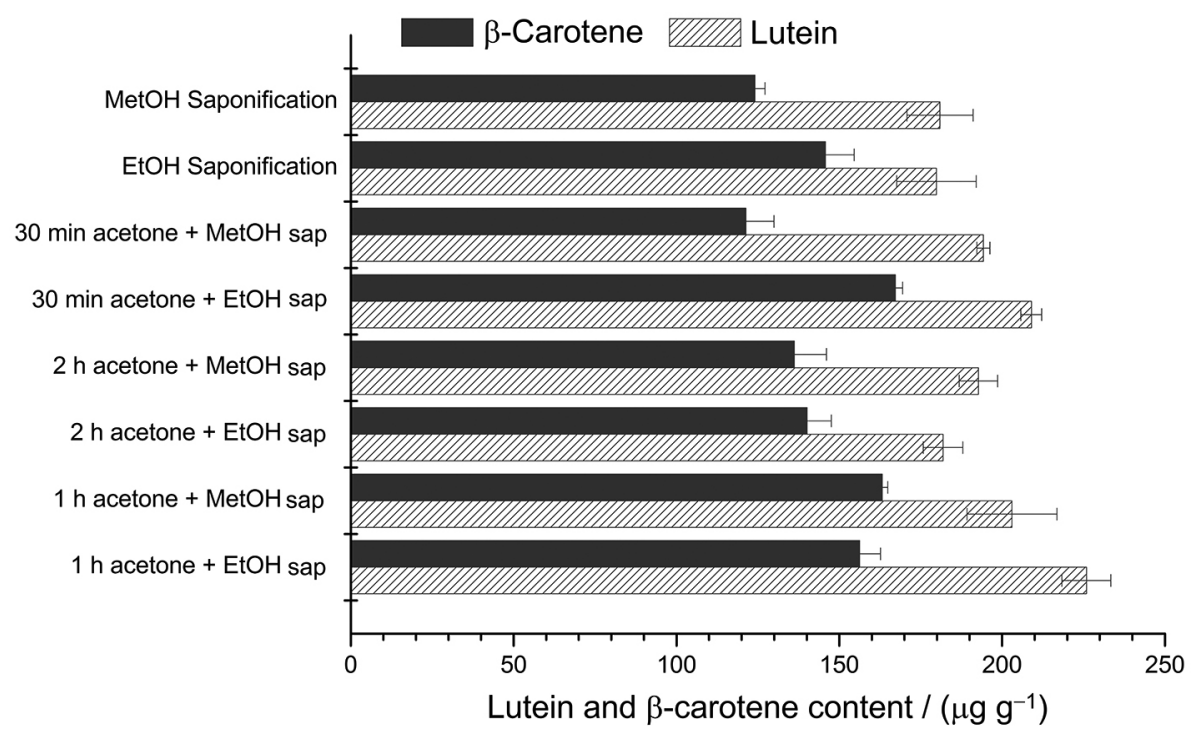

Figure 5: Influence of the methanolic and ethanolic saponification with or without acetone treatment of dry Desmodesmus sp. microalgae on lutein and $\beta$-carotene content. MetOH: Methanol; sap: saponification; EtOH: ethanol. 
treatment biomass, led to a considerable decrease of total pigments yield, around $84.7 \%$ regarding hexane:ethanol $(1: 1, \mathrm{v} / \mathrm{v})$ without any treatment.

Pigment saponification allowed simplified non-esterified pigment chromatographic identification, emerging as an important strategy to be adopted for microalgae pigment analysis; however, it led to lower pigment yields.

Pigments extract stability

After extraction, extract stability in different solvents was evaluated by successive injections until $32 \mathrm{~h}$ after first of each vial. Figure 6 shows the concentration of pigments $\left(\mathrm{mg} \mathrm{mL} \mathrm{mL}^{-1}\right.$ ) expressed in percentage regarding to first injection, with a $100 \%$ extraction yield for chlorophyll $b$ and lutein. $\beta$-Carotene curve stability was not plotted because the peak area from hexane extract presented low concentration values, thus chlorophyll $b$ area was chosen.

Lutein data for first injection in DCM:methanol, DCM and hexane are related to the methanol dissolved extract concentration in the first injection, once this extract provided higher lutein yield. In contrast, for chlorophyll $b$ concentration data are related to DCM dissolved extract. A long term decay in both extracts was observed and it can be related to isomerization and degradation pigments.

For lutein pigment, hexane and DCM extract solution data show good stability, however with low concentration values when compared to methanol and DCM:methanol data. These extracts present decay until $7 \%$ in DCM and between 3 and $8 \%$ in hexane at the first $24 \mathrm{~h}$. The extract in methanol presented higher yield when compared to other studied solvents, with a linear decay of $22 \%$ in its concentration during $32 \mathrm{~h}$. DCM:methanol solution extract exhibited lower stability in the first $8 \mathrm{~h}$, with $31 \%$ reduction in lutein extract when related to first injection, presenting stability since then. Therefore, it was not possible using this solution to maintain the obtained extract from hexane:ethanol $(1: 1, \mathrm{v} / \mathrm{v})$.

Considering chlorophyll $\mathrm{b}$, the extract dissolved in hexane and DCM showed stability with linear decay between first and last injection, corresponding to a $4 \%$ loss in DCM and $16 \%$ loss in hexane in $32 \mathrm{~h}$ after the first injection. For DCM:methanol dissolved extract, there is a large decay (33\%) between first and second injection, however the stability value in the following injections was maintained. The extract dissolved in methanol showed instability, mainly in first $12 \mathrm{~h}$ with $47 \%$ reduction in concentration content. This result for methanol confirms instability obtained by van Leeuwe et al. ${ }^{30}$ for five microalgae species.

The ANOVA indicated that all the extracts tested had a significant effect on peak area of lutein and chlorophyll $b$ concentration. In this experiment, it was also observed differences in the chromatographic profile for different pigments extracts. For the DCM and DCM:methanol dissolved extracts, no large difference was observed;
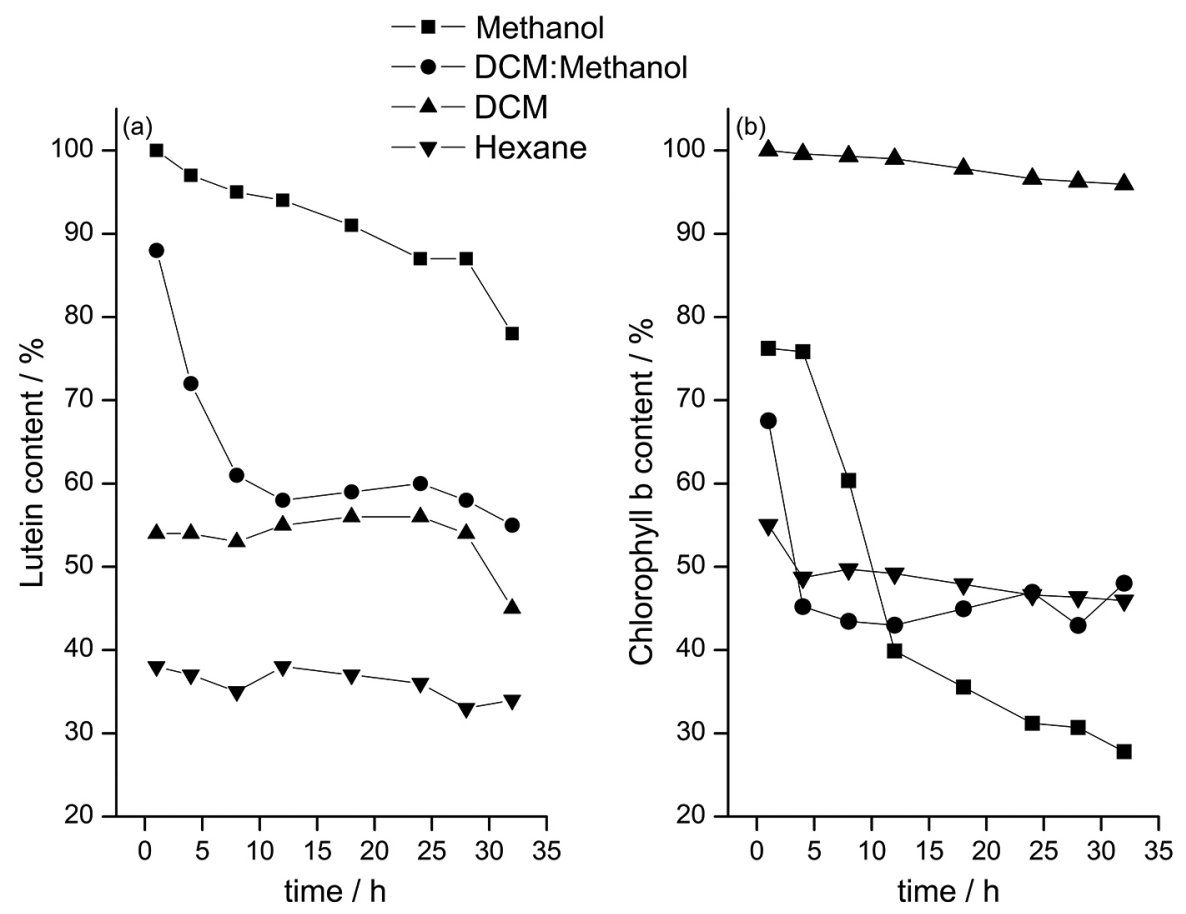

Figure 6. (a) Lutein and (b) chlorophyll b content over $24 \mathrm{~h}$ in extracts from Desmodesmus sp. Pigments content are presented as a percentage of the concentration of the first injection. DCM: Dichloromethane. 
however, DCM:methanol showed higher resolution peaks. Hexane dissolved extract did not present good resolution and separation of peaks in first $35 \mathrm{~min}$ of analysis. The extract dissolved in methanol presented better resolution and separation of chromatographic pigments peaks.

These inequalities in chromatographic profiles among different dissolved extracts affected these pigments concentrations and stability. However, in order to maintain the compound integrity, the use of dissolved extract in methanol until $18 \mathrm{~h}$ after ending extraction was determined, because xanthophyll and carotenes were less affected than chlorophyll. Thus, by determining extract stability time, the appearance of degradation products and compounds structure reorganization are avoided and pigments primary characteristics are maintained.

\section{Conclusions}

For Desmodesmus sp. dry biomass, hexane:ethanol $(1: 1, \mathrm{v} / \mathrm{v})$ biphasic extraction system showed better yields for lutein and $\beta$-carotene when compared to other tested solvents. About extraction times, lutein maximum yield was obtained with 6 extractions of 40 min using hexane:ethanol $(1: 1, v / v)$. For $\beta$-carotene, the best condition occurred with 7 extractions of $40 \mathrm{~min}$. Even though it provided an increase of $\beta$-carotene extraction, pre-treatment of dry biomass with acetone caused a decrement in lutein extraction, making this pre-treatment step commercially unviable.

Saponification before hexane:ethanol $(1: 1, \mathrm{v} / \mathrm{v})$ extraction led to chromatographic profile simplification by converting esterified pigments in free pigments. Pre-treatment with acetone for $1 \mathrm{~h}$ followed by saponification in ethanolic solution and extraction with hexane:ethanol $(1: 1, v / v)$ was the best procedure to obtain better yields when extracting pigments from Desmodesmus sp. dry biomass. Intend an extract with attractive pigments, the saponification method can be adopted because it will facilitate the next steps (separation and purification) to obtain the final compound with high purity.

For the stability tests, the use of methanol dissolved extract up to $18 \mathrm{~h}$ after the end of extraction was determined, because xanthophyll and carotenes pigments were more stable than chlorophyll and affording a better chromatographic profile. Chromatographic analysis allowed identifying that the main pigments available in Desmodesmus sp. are trans-zeanxanthin, chlorophyll $b$, carotenes and trans-lutein. Considering that most industrial processes use only one type of solvent for pigments extraction, the methods tested (hexane:ethanol, saponification and treatment with acetone) improved $\beta$-carotene and lutein yields for Desmodesmus sp.

\section{Acknowledgments}

The authors would like to thank the Ministry of Science, Technology and Innovation (MCTI) for financial support provided by FINEP (Process No. 01.10.0457.00) and CNPq (Process No. 407556/2013-3), CAPES and CNPq for a research productivity grant to Nelson R. Antoniosi Filho (Process No. 312019/2013-0) and FUNAPE for management of financial resources.

\section{References}

1. Aburai, N.; Ohkubo, S.; Miyashita, H.; Abe, K.; Algal Res. 2013, 2, 237.

2. Menezes, R. S.; Soares, A. T.; Lopes, R. G.; Magnotti, C.; Derner, R. B.; Mori, C. C.; Vieira, A. A. H.; Antoniosi Filho N. R.; J. Renewable Sustainable Energy 2015, 7, 043117.

3. Soares, A. T.; Costa, D. C.; Silva, B. F.; Lopes, R. G.; Derner R. B.; Antoniosi Filho, N. R.; BioEnergy Res. 2014, 7, 1035 .

4. Guaratini, T.; Cardozo, H. M.; Pinto, E.; Colepicolo, P.; J. Braz. Chem. Soc. 2009, 9, 1609.

5. Sarkar, C. R.; Das, L.; Bhagawati, B.; Goswami, B. C.; Asian J. Plant Sci. Res. 2012, 2, 546.

6. Solovchenko, A. E.; Chivkunova, O. B.; Semenova, L. R.; Selyakh, I. O.; Shcherbakov, P. N.; Karpova, E. A.; Lobakova, E. S.; Russ. J. Plant Physiol. 2013, 60, 313.

7. Breithaupt, D. E.; J. Agric. Food Chem. 2004, 52, 3870.

8. Inbaraj, B. S.; Chien, J. T.; Chen, B. H.; J. Chromatogr. A 2006, 1102, 193.

9. Kao, T. H.; Loh, C. H.; Inbaraj, B. S.; Chen, B. H.; J. Pharm. Biomed. Anal. 2012, 66, 144.

10. Mendiola, J. A.; Marin, F. R.; Hernandez, S. F.; Arredondo, B. O.; Senorans, F. J.; Ibanez, E.; Reglero, G.; J. Sep. Sci. 2005, $28,1031$.

11. Henriques, M.; Silva, A.; Rocha, J.; Commun Curr. Res. Educ. Top. Trends Appl. Microbiol. 2007, 1, 586.

12. Wang, L.; Weller, C. L.; Trends Food Sci. Technol. 2006, 17, 300 .

13. Wang, J.; Sun, B.; Cao, Y.; Tian, Y.; Li, X.; Food Chem. 2008, 106,804

14. Xiao, X. H.; Wang, J. X.; Wang, G.; Wang, J. Y.; Li, G. K.; J. Chromatogr. A 2009, 1216, 8867.

15. Pasquet, V.; Chérouvrier, J. R.; Farhat, F.; Thiéry, V.; Piot, J. M.; Bérard, J. B.; Kaas, R.; Serive, B.; Patrice, T.; Cadoret, J. P.; Picot, L.; Process Biochem. (Oxford, U. K.) 2011, 46, 59.

16. Kurz, C.; Carle, R.; Schieber A.; Food Chem. 2008, 110, 522.

17. Rezanka, T.; Olsovska, J.; Sobotka, M.; Sigler, K.; Curr. Anal. Chem. 2009, 5, 1.

18. Dey, S.; Rathod, V. K.; Ultrason. Sonochem. 2013, 20, 271.

19. Guillard, R. R.; Lorenzen, C. J.; J. Phycol. 1972, 8, 10. 
20. Goss, R.; Wilhelm, C.; Garab, G.; Biochim. Biophys. Acta, Bioenerg. 2000, 1457, 190.

21. Rosso, V. V.; Mercadante, A. Z.; J. Agric. Food Chem. 2007, 55,5062 .

22. Milenković, S. M.; Zvezdanović, J. B.; Anđelković, T. D.; Marković, D. Z.; Adv. Technol. 2012, 1, 16.

23. Wang, L.; Liu, Y.; Nat. Sci. (Irvine, CA, U. S.) 2009, 1, 23.

24. Hosikian, A.; Lim, S.; Halim, R.; Danquah, M. K.; Int. J. Chem. Eng. 2010, 2010, ID 391632.

25. Lacker, T.; Strohschein, S.; Albert, K.; J. Chromatogr. A 1999, $854,37$.

26. Inbaraj, B. S.; Lu, H.; Hung, C. F.; Wu, W. B.; Lin, C. L.; Chen, B. H.; J. Pharm. Biomed. Anal. 2008, 47, 812.
27. Meléndez-Martínez, A. J.; Vicario, I. M.; Heredia, F. J.; Food Chem. 2007, 104, 169.

28. Meléndez-Martínez, A. J.; Britton, G.; Vicario, I. M.; Heredia, F. J.; Food Chem. 2008, 107, 49.

29. Taher, H.; Al-Zuhair, S.; Al-Marzouqi, A. H.; Haik, Y.; Farid, M.; Biomass Bioenergy 2014, 66, 159.

30. van Leeuwe, M. A.; Villerius, L. A.; Roggeveld, J.; Visser, R. J. W.; Stefels, J.; Mar. Chem. 2006, 102, 267.

Submitted: November 24, 2015 Published online: January 15, 2016 